\title{
Comparative Research on Construction of Art Major Teachers' Team Mainly in Universities of Science and Technology
}

\author{
Linlin Zou \\ College of Arts \\ Northeastern University \\ Shenyang, China
}

\author{
Wanbing Shi \\ School of Humanities and Law \\ Northeastern University \\ Shenyang, China
}

\begin{abstract}
The development of society and economy makes people for the pursuit of art is more urgent and intense, and all aspects of social life in the art industry has become an important part in our daily life, for the social and economic development plays an important role. As an important part of the art of professional personnel training in Universities of science and engineering, it is very an important role for China's art education, has a very important position. The article research the present situation of college art faculty and professional teachers of science and technology, statistics and analysis, through the analysis of the similarities and differences analysis pointed out that China's colleges and universities of science and Engineering in the construction of teachers' team In this paper, the main problems in the process and the direction of the development and construction of the art department and the professional teachers in the universities of science and engineering are put forward.
\end{abstract}

Keywords-universities of science and technology; art major; commonness and difference analysis; experience and enlightenment

\section{INTRODUCTION}

Improvement of living standard turns people's attention from the material field to the spiritual field and artistic field. People's enthusiasm in and pursuit of culture and art produces huge social needs, including not only artwork for people to appreciate but also artistic design of products in all walks of life. Facing a large market demand, China timely establishes the major and the college of art and design in colleges and universities in order to meet this kind of demand. In several decades, China's college of arts develops from nothing, from small to large and from weak to strong, achieving comforting achievements and cultivating large quantities of artistic talent for all industries of society. However, there are some problems in development of China's college of arts. Compared with foreign countries, our talent quality is much worse. Although students of art major in colleges of science and technology have better entrance examination score than students in traditional art academies, teaching staff of the former are weaker. Since construction of front-line teachers' team is closely related to cultivation quality of students majoring in art, this paper intends to conduct an analysis on quality of talent cultivation of China's art major and construction of teachers' team in colleges and universities, including commonness and difference analysis and an analysis on difference in talent cultivation quality of various colleges of arts from the perspective of difference, in order to provide certain experience in construction of teachers' team mainly in college of arts of universities of science and technology. ${ }^{1}$

\section{CurRent Situation OF ARt Major Teachers' \\ TEAM CONSTRUCTION IN UNIVERSITIES OF SCIENCE AND TECHNOLOGY}

In order to learn about current situation of teachers' team construction of art major mainly in universities of science and technology, this paper investigates and analyzes teachers' team structure of art major in China's famous universities of science and technology, including education degree, the title of a technical post, age and teachers' team construction strategy. Those universities of science and technology listed in Project 985 with relatively good art major include Tsinghua University(Institute of Arts and Crafts), Harbin Institute of Technology(Media Technology and Arts Department), Beijing University of Aeronautics and Astronautics(School of New Media Art and Art), Tongji University(School of Art and Design), South China University of Technology(Academy of Arts), Beijing Institute of Technology(School of Art and Design), Northeastern University(College of Arts). Data obtained is as follows:

College of Fine Arts of Tsinghua University: Up to October 2016, it has 198 teachers, including 72 professors and researchers with a senior title, 101 associate professors, associate researchers and senior engineers with a vice-senior title, 24 lecturers and assistant professors with a middle title and 1 teaching assistant. Among them, there are 2 members of the Yangtze River Scholar, 2 national level outstanding teachers and 7 distinguished teachers of Beijing City. Besides, it has 1 national level teaching team and 1 excellent

${ }^{1}$ Hao Xiang, Chen Cuirong. Analysis on Teachers' Team Development and Strategy Effect of China's Colleges and Universities in the Process of Popularization[J]. China Higher Education Research. 2012(05) 
teaching team of Beijing City. Media and Arts Department of Harbin Institute of Technology: Up to the present day, it has 5 professors, 1 associate professor, 8 lecturers and 4 other teachers. Academy of Communications and Arts of Tongji University: Now it has 59 teaching and administrative staff, among whom there are 43 full-time teachers, including 8 professors, 10 associate professors and 22 master supervisors (including cinema college and department of music). In addition, it employs Doctor Li Cong from America's University of Miami, Professor Jans Geelhaar from Germany's Bauhaus University, Professor Giacomo Manzoli from Italy's Bologna University, Professor Wang Xiaohui, a famous German international film and television artists, Professor Yang Jinyue from CCTV, Doctor Qiu Zhenhai from Phoenix Satellite Television and other famous domestic scholars and artists holding the post of guest professors or part-time professors. College of Arts of South China University of Technology: At present, it has 47 fulltime teachers, among whom there are 5 professors, 7 associate professors, 30 lecturers and 5 teaching assistants. There are more than 400 undergraduates and graduate students, among whom there are 33 graduate students. It is equipped with Youth Symphony Orchestra and Symphonic Band of South China University of Technology and College of Arts Chorus and Dance Troupe of South China University of Technology. The college pays extreme attention to inviting top experts and scholars at home and abroad to come to school and to give lectures. It employs 6 foreign guest professors (Lang Lang, Zhou Long, Chen Yi, Xian Xinyi, Zhuo Renxiang and Huang Anlun), and 5 Chinese part-time professors. The college also lays emphasis on enhancing international academic exchange, keeping good cooperative relations with Department of Music of America's Yale University, Department of Music of University of North Texas and other foreign colleges and universities. College of Arts of Beijing Institute of Technology: Up to now, it has 65 front-line teachers and 15 public administration and support staff. Among front-line teachers, there are 2 professors(One is doctoral supervisor), 20 associate professors, 8 doctoral candidates and 49 master degree candidates, including 12 overseas degree owners. In order to improve teachers' academic level and specialty literacy, the college sends nearly 30 teachers to Japan, South Korea, Germany, Australia, Britain, Italy, Thailand etc for further study in the way of visiting scholar, proceeding to the degree, course training class, professional investigation and so on, thus moving overall quality of teachers to a higher level. Apart from front-line teachers, more than half of the college's administrative staff has a master's degree, forming a high level education management team. College of Arts of Northeastern University: Up to the present day, the college has 62 full-time teachers, among whom there are 9 professors and 18 associate professors. $90 \%$ of teachers have a doctor's degree or a master's degree, more than $30 \%$ of whom get their doctor's or master's degree abroad. Several famous scholars with great domestic influence teach here. The college sets up several national level and provincial level excellent courses, video open courses and resource sharing courses with several teachers and students bearing the palm in foreign and domestic competitions. ${ }^{2}$

\section{COMMONNESS ANALYSIS}

Seeing from the above situation of art major's teachers' team of universities of science and technology listed in Project 985, prominent problems are as follows:

- Relatively a small amount of teachers. As to the number of teachers in college of arts of China's famous universities of science and technology, the number is 198 for Tsinghua University, 35 for Harbin Institute of Technology, 18 for Beijing University of Aeronautics and Astronautics, 59 for Tongji University, 47 for South China University of Technology, 65 for Beijing Institute of Technology and 62 for Northeastern University. Seeing from comparisons among the number of recruit student of the above universities' art major over the years, it is clear that there is deficiency in the number of teachers for the above famous universities of science and technology. Compared with student-faculty ratio of other majors, art major relatively has far less teachers, thus making it difficult to ensure high quality of talent cultivation. Among the above universities, only Tsinghua University has more than 100 teachers, accurately speaking, the number is close to 200 . Most of other universities of science and technology has dozens of teachers for art major. Therefore, the outstanding common problem is relatively a small amount of teachers. 3

- Relatively a low proportion of teachers of a high professional rank or with high academic qualifications. Through statistical analysis on the above data, we can know that, in Tsinghua University, $87.37 \%$ of teachers have high-grade professional titles, which is a relatively large proportion. In Harbin Institute of Technology, more than $30 \%$ teachers have high-grade professional titles. In Beijing University of Aeronautics and Astronautics, the percentage is $33.3 \%$. In Tongji University, the percentage is $30.5 \%$. In South China University of Technology, the percentage is $25.5 \%$. In Beijing Institute of Technology, the percentage is $33.8 \%$. In College of Arts of Northeastern University, the percentage is $43.5 \%$. From the above data, we can know that department of colleges and universities has relatively a large proportion of teachers with high-grade professional titles. For example, the percentage of Tsinghua University reaches $87.37 \%$. However, the percentage of arts department of China's other famous universities of science and technology is not more than $87.37 \%$, mostly ranging from $30 \%$ to $40 \%$. In

2 Gong Jiewei. Analysis on Theoretical Basis of Teachers' Team Construction of Art Academy in "Classroom plus Stage" Mode[J]. Intelligence. 2015(27)

3 Wang Wenying. Exploration on Arts' "Double-role" Teachers' Team Construction of Higher Vocational Colleges[J]. Vocational Education(Last Ten-day Periodical). 2013(12) 
some universities, the percentage is even below $30 \%$. Although there is difference, the common problem most universities face is a relatively small proportion of teachers having high-grade professional titles. 4

- In addition, since the above universities' a large quantity of teachers' detailed information is not available, a comprehensive and effect analysis on teachers' education background can't be done. According to incomplete statistics, in the above universities, teachers with a doctor's degree increase on a yearly basis. However, as a whole, there are still a relatively small number of teachers with a doctor's degree and the average percentage is around $60 \%$. The percentage for some universities is $80 \%$ to $90 \%$. Difference exists in across comparison. The common situation is that teachers with a doctor's degree occupy a relatively small percentage, which needs to be improved through talent introduction and teachers' training.

\section{DIFFERENCE ANALYSIS}

Through statistical analysis on teachers' team structure of the above mentioned universities of science and technology, this paper points out, researches and discusses the common problem. As to difference analysis, this paper selects two representative teachers' teams, based on which the difference analysis is conducted. The two chosen universities are Northeastern University and Beijing Institute of Technology. College of Arts of Northeastern University places particular emphasis on artistic theory research with two grassroots academic organizations: department of music and department of design. Department of music provides musical performance major(including major fields of piano, vocal music, Chinese musical instruments and western instruments, 4 in total) while department of design has two undergraduate programs: environmental design and visual communication design. College of Arts of Beijing Institute of Technology places particular emphasis on engineering courses with department of visual communication design, department of environmental art design, department of culture heritage, department of decorative painting and department of traditional art and crafts. It is formally established in 2002 and gradually develops into the comprehensive major development pattern relying on science and engineering and combining design with art. In terms of major setup and the goal of talent cultivation, Northeastern University lays particular emphasis on theoretical research while Beijing Institute of Technology places particular attention on engineering practice, being more inclined to combination with market requirement. Therefore, in terms of construction of teachers' team, the former emphasizes taking theory as the basis while the latter emphasizes market-oriented and engineering practice oriented, which can be seen from

4 Xu Xiaohua. Research on International Construction of Teachers' Team of Art Institute of Higher Learning[J]. Human Resource Management. 2013(12) relevant research directions of teachers on these two universities' official homepage.

\section{EXPERIENCE AND ENLIGHTENMENT PROVIDED BY \\ TEACHERS' TEAM CONSTRUCTION FOR UNIVERSITIES OF SCIENCE AND TECHNOLOGY}

Through commonness and difference analysis on college of arts and professional teachers' team construction of China's famous universities of science and technology, we have a clear picture of college of arts in universities of science and technology and the entirety and structure of professional teachers' team. Through statistical analysis, existing problems in teachers' team construction of China's universities of science and technology become clear, providing enlightenment for teachers' team construction of China's art academy. Experience and enlightenment obtained are as follows:

\section{A. Urgent Need to Enlarge the Number of Teachers}

Seeing from the above statistical data, the outstanding problem existing in art colleges and art major of China's universities of science and technology is the too small number of teachers, which is highly reflected in comparison with other majors. Compared with some departments with excellent talent cultivation quality, the faculty-student ratio of art colleges of universities of science and technology is much lower. Sufficient teachers can guarantee carrying out of normal teaching activities, formulation of training program and various practical teaching activities and scientific research activities in terms of the aspect of teacher resource. Therefore, at present, the outstanding problem of art colleges of China's universities of science and technology is the small number of teachers, which can be solved through talent introduction for colleges and universities. ${ }^{6}$

\section{B. Urgent Need to Optimize the Structure of Teachers, Professional Title}

In Tsinghua University, the proportion of teachers with high professional titles is $87 \%$. Teachers with high professional titles are equipped with good teaching skills, abundant theory and rich practice, which are of significant importance to cultivation of students in art academies. Therefore, Tsinghua University graduates have an extremely high quality, coming out top in various international rankings. Compared with Tsinghua University, the percentage of teachers with high professional titles in China's other famous universities of science and technology is not so reasonable and most of their percentage ranges from $30 \%$ to $40 \%$. Improving the proportion of teachers with high professional titles plays a direct positive role in talent cultivation of art major. Therefore, we should optimize and improve the structure of professional title, and encourage teachers to dig into teaching methods and to conduct relevant scientific

\footnotetext{
5 Zhang Shaohua. "Double-role" Teachers' Team Construction in Higher Vocational Education of Art[J]. Chinese Culture Forum. 2013(08)

${ }^{6} \mathrm{Hu}$ Yongmei, Yang Mei, Liang Dawan. Art Academy's Teachers' Team Construction and Management Study under the Background of Cultural Development and Prosperity[J]. Education and Teaching Research. 2013(07)
} 
researches to construct teachers' team and to improve its structure of professional title. ${ }^{7}$

\section{Urgent Need to Optimize Teachers' Educational Background Structure}

Through the above statistics, we can know that the proportion of teachers with a doctor's degree is not high generally. Many academies start to pay attention to this problem and try to enhance the proportion through talent introduction or providing favorable policies for internal teachers to enable them to engage in advanced studies to get a doctor's degree. ${ }^{8}$

\section{Attach Importance to Theory and Practice}

Through difference analysis, we can know that some colleges emphasize theory while some colleges emphasize market-oriented engineering practice in the process of teachers' team construction. Different majors may differ in theory and practice. But we must notice that the basis of theory and practice is to guide practice which in turn boosts development of theory. Therefore, we must emphasize enhancement of teachers' theoretical level in the process of teachers' team construction, which can be realized through setting up the project to support theoretical research. The final purpose of theory is to help students get employed in market. Therefore we should combine practice with market demand, thus finally realizing comprehensive development and progress of teachers' team.

\section{CONCLUSION}

This paper researches and analyzes current situation of art colleges' teachers' team construction in China's universities of science and technology and finds out some common problems existing in the process of art major's teachers' team construction in China's universities of science and technology, like a relatively small amount of teachers, a low proportion of teachers with a senior title or with a doctor's degree and so on. In terms of talent cultivation direction in teachers' team construction, some colleges emphasize theoretical research while some emphasize market demand oriented practice and application research. Discovery of these problems brings significant enlightenment to art major's teachers' team construction in China's universities of science and technology, during the process of which those universities need to adopt talent introduction or internal training to accomplish adjustment of teachers' team structure, to optimize teachers, to bring in new teachers and to enhance the proportion of teachers with a doctor's degree or a senior title, thus providing powerful

7 Chen Liyuan. High-level Demonstration Higher Vocational College's Teachers' Team Construction Research[J]. China Education Innovation Herald. 2013(16)

$8 \mathrm{Li}$ Xianling, Zhang Zhiping, Gao Hongyan. A Rustic Opinion on Professional Teachers' Team Construction of Higher Vocational College[J]. Education Development Research. 2012(17)

${ }^{9}$ Chen Xiaoli. Discussion on Internal and External Reasons Why "Doublerole" Teachers' Team with Middle Title Develops Slowly[J]. Modern Communication. 2012(07) intellectual support for cultivation of students majoring in art in universities of science and technology.

\section{REFERENCES}

[1] Gong Jiewei. Analysis on Theoretical Basis of Teachers' Team Construction of Art Academy in "Classroom plus Stage" Mode[J]. Intelligence. 2015(27)

[2] Wang Wenying. Exploration on Arts' "Double-role" Teachers' Team Construction of Higher Vocational Colleges[J]. Vocational Education(Last Ten-day Periodical). 2013(12)

[3] $\mathrm{Xu}$ Xiaohua. Research on International Construction of Teachers Team of Art Institute of Higher Learning[J]. Human Resource Management. 2013(12)

[4] Zhang Shaohua. "Double-role" Teachers' Team Construction in Higher Vocational Education of Art $[\mathrm{J}]$. Chinese Culture Forum. 2013(08)

[5] Hu Yongmei, Yang Mei, Liang Dawan. Art Academy's Teachers' Team Construction and Management Study under the Background of Cultural Development and Prosperity[J]. Education and Teaching Research. 2013(07)

[6] Chen Liyuan. High-level Demonstration Higher Vocational College's Teachers' Team Construction Research[J]. China Education Innovation Herald. 2013(16)

[7] Li Xianling, Zhang Zhiping, Gao Hongyan. A Rustic Opinion on Professional Teachers' Team Construction of Higher Vocational College[J]. Education Development Research. 2012(17)

[8] Chen Xiaoli. Discussion on Internal and External Reasons Why "Double-role" Teachers' Team with Middle Title Develops Slowly[J]. Modern Communication. 2012(07)

[9] Hao Xiang, Chen Cuirong. Analysis on Teachers' Team Development and Strategy Effect of China's Colleges and Universities in the Process of Popularization[J]. China Higher Education Research. 2012(05)

[10] Pan Chi, Yue Shuzhen. Research on Teachers' Team Construction of Higher Vocational Colleges[J]. Economic Research Guide. 2012(06)

[11] Zheng Caihong. Construction of Part-time Teachers' Team Construction of Higher Vocational Colleges-Take Environment Arts Department of Suzhou Institute of Arts and Crafts as An Example[J]. Kaifeng Institute of Education Journal. 2014(10). 